\title{
Micro propagación de variedades nativas de cacao (Theobroma cacao) mediante embriogénesis somática
}

\author{
Henry Omar Calderón Acuña ${ }^{1}$ - María Elena Montes de Godoy ${ }^{2}$
}

Recepción: 23/01/2017

Aceptación: 20/03/2017

\section{Resumen}

El cultivo del cacao (Theobroma cacao), en épocas precolombinas, fue de importancia económica y cultural en El Salvador; pero debido a las inclemencias del tiempo sobre la población nativa, parte del conocimiento sobre el cultivo del cacao se perdió. En la actualidad se pretende reactivar los campos de cacao en algunas fincas del país, ya que muchos de los bosques cafetaleros se deterioraron por causa de la Roya, enfermedad provocada por el hongo Hemileia vastatrix. Debido a este problema, se decidió implementar un sistema de micropropagación de árboles de cacao nativos de El Salvador para establecer un protocolo de rescate de materiales autóctonos; y posteriormente, facilitar la propagación mediante la técnica de embriogénesis somática. En este ensayo se evaluaron tres dosis de glucosa, siendo 10, 20 y 30 $\mathrm{g} \mathrm{L}^{-1}$, como fuente de carbón en el medio de cultivo, y cuatro dosis de 2-4D (Ácido 2-4 diclorofenoxiacético), siendo $0.0,1.0,2.0$ y $3.0 \mathrm{ml} \mathrm{L}^{-1}$; esta auxina interviene en la callogénesis de los explantes de cacao. El medio de cultivo utilizado fue DKW (Driver y Kiniyuki et al., 1984). El mejor tratamiento para la regeneración de callos se obtuvo con la dosis de $20 \mathrm{~g} \mathrm{~L}^{-1}$ de glucosa y $2.0 \mathrm{ml} \mathrm{L}^{-1}$ de $2-4 \mathrm{D}$. Se realizó un Análisis de Varianza (ANOVA) con comparación de medias por Tukey y Test de Rangos Múltiples; además se empleó el programa estadístico Statgraphics Centurion XVI.I para el análisis de los datos.

Palabras clave: embriones somáticos, callogénesis, 2-4 diclorofenoxiacético, explante, estaminoides, glucosa

\begin{abstract}
The cocoa farming (Theobroma cacao), in pre-Columbian times, had a financial and cultural importance in El Salvador, but due to the inclement weather on the native population, part of the knowledge about the cocoa farming was lost. Nowadays, it is intended to reactivate the cocoa fields in some farms of the country because many coffee forests were damaged by Roya, disease caused by the fungus Hemileia vastatrix. Because of this problem, it was decided to implement a micro-propagation system of native cocoa trees in El Salvador in order to establish a protocol of rescuing native materials and subsequently to facilitate propagation thought somatic embryogenesis. In this practice were evaluated three doses of glucose that are 10,20 and $30 \mathrm{~g} \mathrm{~L}^{-1}$ as a carbon source among the farming and four doses of 2-4D (Acid 2-4 dichlorophenoxyacetic) that are 0.0, 1.0, 2.0 and 3.0 $\mathrm{ml} \mathrm{L}^{-1}$. This auxin infers in the callogenesis of the cocoa explants. The growing medium implemented was DKW (Driver and Kiniyuki et al., 1984). The best treatment to the calluses regeneration was obtained with the doses of $20 \mathrm{~g} \mathrm{~L}^{-1}$ of glucose and $2.0 \mathrm{ml} \mathrm{L}^{-1}$ of 2-4D. It was made an Analysis of Variance (ANOVA) with comparison of averages by Turkey and Test of multiple ranges. Moreover, it was implemented the statistic program Statgraphics Centurion XVI.I to the data analysis.
\end{abstract}

Key words: somatic embryons, callogenesis, 2-4 dichlorophenoxyacetic, explant, estamonioid, glucose

1. Ingeniero Agrónomo, Investigador; Universidad Católica de El Salvador, El Salvador email: henry.calderon1@catolica.edu.sv 2. Maestra en Horticultura, Docente investigadora; Universidad Católica de El Salvador, El Salvador email: maria. montes@catolica.edu.sv 


\section{Introducción}

Theobroma cacao es el nombre científico que recibe el árbol del cacao o cacaotero, planta de hoja perenne de la familia Malvácea, antiguamente incluida en la familia Esterculiácea. Theobroma, significa en griego "alimento de los dioses"; cacao se deriva del náhuatl, "cacáhua".

El cultivo del cacao en El Salvador no es nada nuevo: antes y durante la conquista Española fue uno de los centros de mayor producción y venta de cacao. Es así como la región de Izalco se volvió tan importante para los españoles. En documentos de la Colonia, se especifica la producción de cacao en las manos de los nativos, quienes posteriormente dejaron de cultivarlo por varias razones como las constantes erupciones del volcán de Izalco, disminución de la población indígena debido a nuevas enfermedades y otros. El cacao fue cultivado y consumido en esta área desde hace más de 3,000 años. Los Pueblos Mayas que habitaron Mesoamérica (lo que ahora es el Sur de México, Guatemala, Belice, Honduras y Occidente de El Salvador), fueron los que domesticaron el cacao, ya que perfeccionaron las técnicas del cultivo, aprendieron a curar y mantener las semillas en buenas condiciones para elaborar una bebida de sumo agrado al paladar. Este no sólo lo usaban en sus ceremonias, sino que también lo ocuparon como moneda. Mucho antes que los espa- ñoles conquistaran lo que hoy es El Salvador (1524), el uso del cacao era generalizado por toda Mesoamérica (ESCACAO, 2009).

En el año 2014, se aprobó en El Salvador un proyecto denominado "alianza cacao" con apoyo de USAID (United States Agency International Development) y CRS (Catholic Relief Services); esta alianza contempla el cultivo del grano en 10 mil hectáreas de 83 municipios del territorio nacional, con lo que las autoridades esperan generar unos 26,570 empleos directos e indirectos y beneficiar a cerca de 10 mil familias de productores de cacao (Machuca, 2014). Por otro lado, Hecht (2014), considera que, con la crisis actual del café, está la oportunidad de integrar otros cultivos a las fincas, y uno de estos es el "cacao fino y de aroma", cultivado de forma moderna y tecnificada, aprovechando la sombra ya existente y los buenos suelos dentro de los cafetales. En diferentes ocasiones, Ángel (2014) especialista agrícola de la Fundación Salvadoreña para el Desarrollo Económico y Social (FUSADES), ha sugerido el cultivo de cacao como una opción que merece consideración en las zonas de café de bajío (400-800msnm), destacando la importancia del cultivo en el aspecto económico, social y ambiental.

Desde el punto de vista del mejoramiento genético, la clonación del cacao se considera una etapa necesaria para optimizar la explotación de los beneficios directos de un geno- 
tipo seleccionado, que responda a los requerimientos de resistencia a los fitoparásitos, altos rendimientos y alta calidad chocolatera (López-Baez, 1996). En este sentido, los trabajos que se desarrollan actualmente en varias instituciones se orientan al perfeccionamiento de diferentes técnicas de propagación in vitro, entre las que se encuentra la embriogénesis somática (López-Baez et al., 2001). Estas técnicas permitirían la propagación de plantas sanas con calidad genética (cacao fino de aroma) y en un corto período de tiempo.

\section{Materiales y Métodos}

El ensayo se realizó en el Laboratorio de Cultivo de Tejidos Vegetales de la Universidad Católica de El Salvador. La colecta de botones florales de cacao se llevó a cabo en la zona central del departamento de Ahuachapán, a partir de árboles adultos ubicados en la zona urbana de la ciudad a $815 \mathrm{msnm}$, a una hora en específico (alrededor de las 6:00 a.m.). Se colectaron 20 botones florales del árbol seleccionado, eligiendo los que aún se encontraban cerrados (figura 1), con un tamaño aproximado entre el rango de $6 \mathrm{y}$ $8 \mathrm{~mm}$, los cuales fueron introducidos inmediatamente en un frasco con agua estéril. Cada frasco se colocó en una hielera para su trasporte al laboratorio.

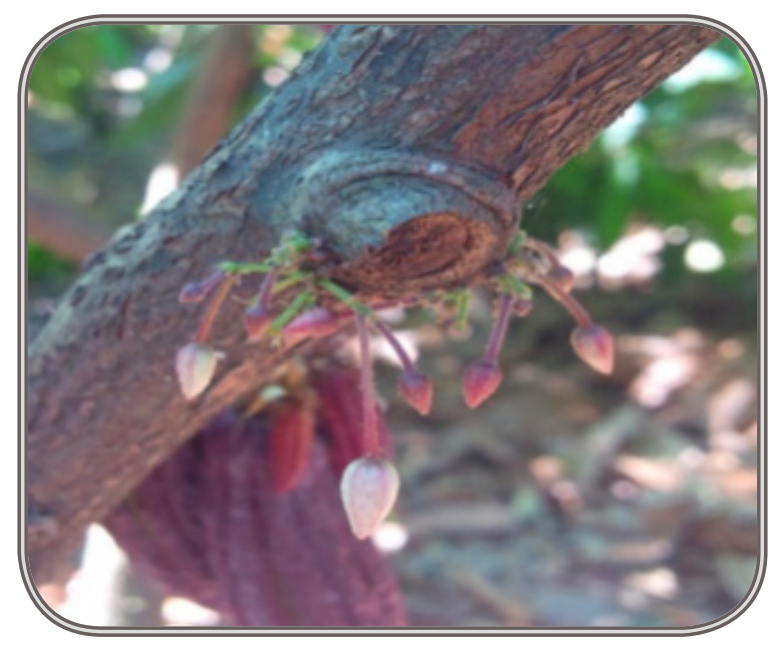

Figura 1. Botones florales de cacao (Theobroma cacao) de fenotipo criollo, utilizados para micropropagación en condiciones de laboratorio.

En el laboratorio se colocaron todos los botones florales en un solo recipiente; y se agregaron tres gotas de tween 80 , además se lavaron tres veces con agua desmineralizada estéril. Luego se preparó una solución de Amistar (Azoxistrobina) al $0.2 \%$ con tres gotas de tween 80 en la que se introdujeron los botones florales y se dejaron reposar durante 30 minutos.

Posteriormente, los botones florales se transfirieron a una solución de hipoclorito de calcio durante veinte minutos en cámara de flujo laminar, en donde se aplicaron tres enjuagues con agua desmineralizada estéril. Luego se procedió a disectar los botones florales de cacao y separar los pétalos y estaminodios, e introducirlos en terreno de cultivo PCG (Primary Callus Medium), en diferentes concentraciones de glucosa $(10,20$ y $30 \mathrm{~g} \mathrm{L-1})$ y 2,4 $\mathrm{D}(0.0,1.0,2.0,3.0 \mathrm{ml} \mathrm{L-1})$ para inducir a la formación de callos. 
A los quince días de permanecer en estas condiciones, cada callo embriogénico se transfirió al terreno de cultivo SCG (Secondary Callus Growth Medium) (figura 2a). Luego de otros quince días, los callos embriogénicos friables se transfirieron individualmente al terreno de cultivo ED (Embryo Development Medium) para la generación de embriones. Cada veintiún días se cambió el medio de cultivo $\mathrm{ED}$ a medio de cultivo ED nuevo, durante dos veces consecutivas; al tercer cambio de medio se utilizó medio de cultivo ED líquido y semisólido (figura 2b) para observar la generación y crecimiento de embriones, (ver figura 2).

Una vez que los embriones alcanzaron una longitud de $1 \mathrm{~cm}$, con cotiledones diferenciados (figura 3a), se transfirieron al medio de cultivo líquido PEC (Primary Embryo Conversion Medium), en biorreactor de inmersión temporal (BIT), para estimular la conversión a plantas (Figura 3b). El tiempo de inmersión fue de un minuto cada cuatro horas.

El diseño experimental consistió en un diseño completamente al azar con arreglo factorial, en donde los factores fueron doce tratamientos (cuadro 1); producto de la combinación de distintas dosis de glucosa (factor A): 10, $20,30 \mathrm{~g}$ L-1 y $2-4 \mathrm{D}$ (factor B) en dosis de: 0.0, $1.0,2.0$ y $3.0 \mathrm{ml} \mathrm{L}-1$, (ver figura 3 ). 


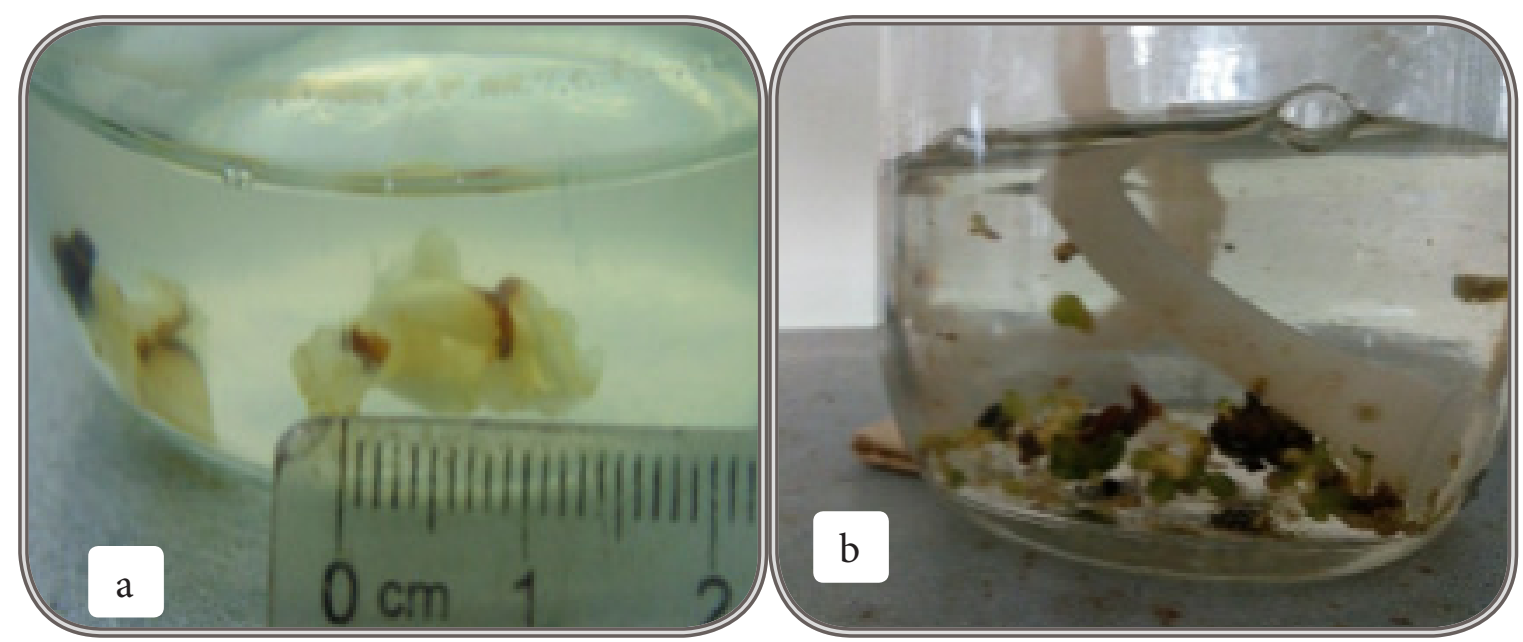

Figura 3. Embriones de cacao (Theobroma cacao) en fase de desarrollo, a) Embriones de una longitud de $1 \mathrm{~cm}$. en medio líquido, luego de 65 días de siembra; b) Embriones en biorreactor (BIT) para su conversión a plantas, después de seis meses de siembra inicial.

Tabla 1. Conformación de tratamientos según los niveles de los factores en estudio

\begin{tabular}{|l|l|l|l|l|}
\hline \multicolumn{1}{|c|}{ Factor B } & \multicolumn{1}{c|}{$\mathbf{0 . 0}$} & \multicolumn{1}{c|}{$\mathbf{1 . 0}$} & $\mathbf{2 . 0}$ & $\mathbf{3 . 0}$ \\
\hline Factor A & & & & \\
\hline $\mathbf{1 0}$ & T1 $(10,0.0)$ & T2 $(10,1.0)$ & T3 $(10,2.0)$ & T4 $(10,3.0)$ \\
\hline $\mathbf{2 0}$ & T5 $(20,0.0)$ & T6 $(20,1.0)$ & T7 $(20,2.0)$ & T8 $(20,3.0)$ \\
\hline $\mathbf{3 0}$ & T9 $(30,0.0)$ & T10 $(30,1.0)$ & T11 $(30,2.0)$ & T12 $(30,3.0)$ \\
\hline
\end{tabular}

El análisis estadístico se realizó mediante un análisis de: varianza (ANOVA), comparación de medias por Tukey y Test de Rangos Múltiples. Para el análisis de datos se empleó el programa estadístico Statgraphics Centurion XVI.I.

Las unidades experimentales fueron: 240 frascos producto de los doce tratamientos establecidos y veinte repeticiones por cada tratamiento. Se utilizaron cinco explantes (pétalos y estaminoides) por cada frasco.

\section{Resultados y Discusión}

Se utilizaron doce tratamientos producto de las combinaciones de los niveles del Factor A y el Factor B de las dosis de glucosa y 2-4D. Cada tratamiento empleado produjo callos en los explantes de las inflorescencias extraídas del árbol de cacao; en cada tratamiento se pudo observar la influencia de la glucosa (crecimiento) y el 2-4D (formación) en los callos generados. Los tratamientos que desarrollaron menos callos fueron los que tenían $0.0 \mathrm{ml} \mathrm{L}^{-1}$ de $2-4 \mathrm{D}$, ya que no se concretó una 
formación adecuada en los explantes, pero a medida que se aumentó la dosis de glucosa $\left(10,20,30 \mathrm{~g} \mathrm{~L}^{-1}\right)$, se observó mínimo desarrollo de callos en los explantes, principalmente en los estaminoides, los cuales a los quince días se mostraron turgentes; y a los veinticinco días, empezaron a generar callos. Los explantes que no respondieron al tratamiento de $0.0 \mathrm{ml} \mathrm{L}^{-1}$ de $2-4 \mathrm{D}$ fueron los pétalos, ya que sólo se mostraron turgentes a los quince días después de la siembra, y a los veinte días se necrosaron.

Durante el experimento se observó que a medida que se aumentaba la dosis de 2-4D, mayor es la formación de callos en los explantes; y a medida que se aumenta la dosis de glucosa, mayor es el incremento del tamaño del ca1lo. Por lo tanto, al combinarse la glucosa con el 2-4D, cada tratamiento establecido generó callos, con una diferencia significativa entre las medias correspondientes al número de callos generados por tratamiento.
Se realizó Análisis de Varianza (ANOVA) con un nivel de confianza de $95 \%$ para determinar si existían diferencias significativas, entre las medias de cada tratamiento.

En la gráfica de límites de decisión (figura 4), se observa cuales tratamientos resultaron más eficientes para generar callos en los explantes. Como resultado se determinó que el tratamiento que más generó callos fue T8 con un promedio de 4.1 callos generados por frasco; sin embargo, en la etapa de desarrollo de embriones no se obtuvo resultados favorables. Se observó que el mejor tratamiento para generar callos fue el tratamiento T7 con un promedio de 3.15 callos generados por frasco, debido a la friabilidad que presentó cada callo en la etapa de generación de embriones, estos posteriormente generaron embriones somáticos.

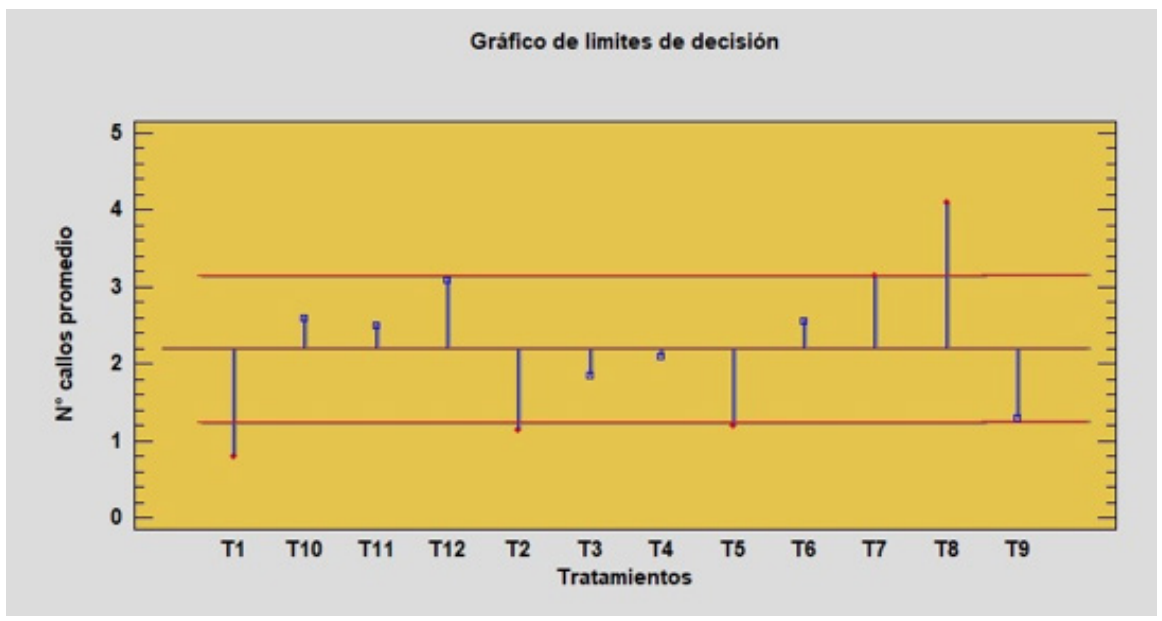

Figura 4. Gráfica para número de callos generados al final de veinticinco días, con un $95 \%$ de límites de decisión, correspondiente a doce tratamientos con arreglo combinatorio de dosis de glucosa y 2-4D. 


\section{Conclusiones}

Según Díaz-López et al., (2009), en la embriogénesis de cacao, el genotipo es un factor que afecta la obtención de embriones, puesto que interactúa con otros como el tamaño del botón floral, la concentración de azúcares en el medio de cultivo (Aguilar 1990; Chanatásig 2004; Velásquez et al. 2006; Traore y Guiltinan 2006; Díaz-López et al. 2009), el tipo de explante (Maximova et al. 2002; Velásquez et al. 2006; Traore y Guiltinan, 2006; Minyaka et al. 2008; Solano 2008), la concentración de diferentes componentes del medio de cultivo ( $\mathrm{Li}$ et al., 1998; Minyaka et al. 2008; Chanatásig 2004).

La técnica que se utilizó para generar la embriogénesis somática en cacao fue similar a la empleada por López-Baez et al. (1993), en donde se utilizaron como explantes principales los pétalos y los estaminoides de la inflorescencia de cacao, ya que el cacao es una planta alógama, por lo que los cotiledones llevan implícita una variabilidad natural producto de su cruzamiento; aunque los mismos se pueden utilizar cuando se parte de cruzamientos conocidos. El medio de cultivo que se utilizó para la embriogénesis somática fue el DKW ya que es uno de los más eficientes, en donde se adiciona en la primera parte del proceso glucosa como principal fuente de carbono, según lo describe López-Baez et al. (1993), Li et al. (1998) y Maximova et al. (2002).
Según los resultados obtenidos para la variedad de cacao criollo estudiada, es necesario emplear de 1 a $2 \mathrm{ml} \mathrm{L}^{-1}$ de $2-4 \mathrm{D}$ para generar callos en la primera etapa del proceso, ya que, si no se adiciona, la generación de callos es muy pobre. Trabajos similares se describen por Li et al., (1998) y Maximova et al. (2002), quienes utilizaron explantes de la inflorescencia de cacao a través de la embriogénesis somática, logrando la producción de embriones de doce genotipos de cacao diferentes. Los mejores resultados se obtuvieron utilizando $2-4 \mathrm{D}$; sin embargo, si la dosis de $2-4 \mathrm{D}$ es incrementada, aumenta la producción de callos, pero no generan embriones. De acuerdo a Elhag et al. (1988), el 2-4D no es esencial para la embriogénesis somática de cacao, pero puede incrementarla en algunos clones utilizando bajas concentraciones.

En cuanto a las concentraciones de glucosa, cabe destacar que es una fuente de carbono precursora de la callogénesis, ya que Li et al. (1998) y Maximova et al. (2002), determinaron que la glucosa como fuente de carbono da efectos positivos en la callogénesis. En el tratamiento T9 con dosis de $30 \mathrm{~g} \mathrm{~L}^{-1}$ y $0.0 \mathrm{ml} \mathrm{L}^{-1}$ $2-4 \mathrm{D}$, se pudo apreciar que generó, en cierto grado, una cantidad considerable de callo en comparación con los demás tratamientos. 


\section{Referencias}

Aguilar, M. (1990). Obtención de plantas de cacao (Theobroma cacao L.) a partir del microinjerto de embriones somáticos. Tesis M.Sc. Turrialba, CR. Centro Agronómico Tropical de Investigación y Enseñanza; p.131

Ángel, A. (24 de febrero de 2014). ElSalvador.com. Recuperado de http://www.elsalvador.com/ articulo/negocios/diversifican-cultivos-cafetales-con-cacao-fino-aroma-49512

Chanatásig, C. (2004). Inducción de la embriogénesis somática en clones superiores de cacao (Theobroma cacao L.), con resistencia a enfermedades fungosas. Tesis M.Sc. Turrialba, CR. Centro Agronómico Tropical de Investigación y Enseñanza; p. 86

Díaz-López, A; Velásquez, R; Chirinos, M. (2009). Efecto del tamaño del botón floral sobre la inducción de embriones somáticos en cacao. Agronomía Trop. Vol. 59(4):481-489.

Driver, JA; Kuniyuki, AH. (1984). In vitro propagation of Paradox walnut rootstock. HortScience. Vol. 19, pp. 507-509.

Elhag, H; Whipkey, A; Janick, J. (1988). Factors Affecting Asexual Embryogenesis Via Callus in Theobroma cacao L. Agril. Biol Sci. Vol. 6(1), pp. 31-43.

Sociedad Cooperativa de Productores de Cacao de El Salvador de R. L. y C. V. (ESCACAO) (2009). Granos de cacao fino y de aroma de El Salvador. Recuperado de http://www. escacao.com/ES_CACAO_Historia.html

Hecht, T. (24 de Frebrero de 2014). ElSalvador.com. Recuperado de http://www.elsalvador.com/ articulo/negocios/diversifican-cultivos-cafetales-con-cacao-fino-aroma-49512

Hecht, T. (15 de Febrero de 2014). Sociedad Cooperativa de Productores de Cacao de El Salvador de R. L. y C. V. (ESCACAO). Recuperado de http://www.escacao.com/

Li, Z; Traore, A; Maximova, S; Guiltinan, M. (1998). Somatic embryogenesis and plant regeneration from floral explants of cacao (Theobroma cacao L.) using thidiazuron In Vitro Cell. Dev. Biol.-Plant. Vol. 34; pp. 293-299. 
Lopez-Báez, O. (1996). Biotecnologías Aplicadas al Mejoramiento Genético y propagación de Cacao. Actas de la IX Reunión Científica, Tecnológica, Forestal y Agropecuaria. México. Tabasco. Villa Hermosa: p. 176-171

López-Báez, O; Moreno, J; Pacheco, S. (2001). Avances en Propagación de Cacao- Theobroma cacao- por Embriogénesis Somática en México. In Ingenic. Proceedings of the International Workshop on new Technologies and Cocoa Breeding. Malaysia. Ingenic; p. $163-176$.

López-Baez, O; Bollon, H; Eskes, A; Pétiard, V. (1993). Embryogenese Somatique de cacayer (Theobroma cacao) a partir de piéces florales. Compte-Rendus de L'Académie de Sciences. Vol. 316; pp. 579-584.

Machuca, E. (4 de Diciembre de 2014). ElSalvador.com. Recuperado de http://www.elsalvador. com/articulo/negocios/lanzan-alianza-cacao-con-apoyo-usaid-crs-59495

Maximova, S; Alemanno, L; Young, A; Ferreiere, N; Traore, A; Guiltinan, M. (2002). Efficiency, genotypic variability and cellular origin of primary and secondary somatic embryogenesis of Theobroma cacao L. In Vitro Cell. Dev. Biol._Plant. Vol. 38; pp. 252-259

Minyaka, E; Niemenak, N; Fotso; Sangare, A; Ndoumou, D. (2008). Effect of MgSO4 and K2SO4 on somatic embryo differentiation in Theobroma cacao L. Plant. Cell. Tiss. Organ. Cult. Vol. 94; pp. 149-160.

Solano, W. (2008). Embriogénesis somática de clones superiores de cacao (Theobroma cacao L.) obtenidos en el Programa de Mejoramiento Genético del CATIE. Tesis M.Sc. Turrialba, CR. Centro Agronómico Tropical de Investigación y Enseñanza; p. 92

Traore, A; Guiltinan, M. (2006). Effects of carbon source and explant type on somatic embryogenesis of four cacao genotypes. HortScience Vol. 41(3); pp. 753-758

Velásquez, R; Sandrea, Y; Betancourt, C; Mata, J; García, F. (2006). Embriogénesis somática en cultivares de cacao venezolanos. Agronomía Trop. Vol. 56(1); pp. 61-74. 